\title{
Patient Factors Which Contribute to Non-adherence to TB Treatment in Kericho and Nakuru Counties of Kenya
}

\author{
Richard Kiplangat Arap Sang ${ }^{1}$, Ronald Omenge Obwoge ${ }^{1}$, Simon Kangethe $^{2}$, Laban Peter Ayiro ${ }^{3}$, \\ Johnson Masai Changeiywo ${ }^{4}$ \\ ${ }^{1}$ Community Health Department, Faculty of Health Sciences, Egerton University, Nakuru, Kenya \\ ${ }^{2}$ Medical Education, Moi University, Eldoret, Kenya \\ ${ }^{3}$ Moi University, Quality Assurance, Eldoret, Kenya \\ ${ }^{4}$ Instruction and Educational Management Department, Egerton University, Nakuru, Kenya
}

Email address:

drsangrich@gmail.com (R. K. A. Sang),drsangrich@yahoo.com (R. K. A. Sang)

\section{To cite this article:}

Richard Kiplangat Arap Sang, Ronald Omenge Obwoge, Simon Kangethe, Laban Peter Ayiro, Johnson Masai Changeiywo. Patient Factors Which Contribute to Non-adherence to TB Treatment in Kericho and Nakuru Counties of Kenya. Science Journal of Public Health. Vol. 5, No. 4, 2017, pp. 329-334. doi: 10.11648/j.sjph.20170504.18

Received: April 25, 2017; Accepted: May 15, 2017; Published: July 3, 2017

\begin{abstract}
Tuberculosis (TB) continues to be a major cause of high morbidity and mortality in Kenya. Adherence to TB treatment is one of the interventions that lead to increase in cure rate thus reducing mortality and emergence of Multi drug resistant tuberculosis (MDR) and high cost of treatment. This study focused on TB patients in urban and rural areas of Kericho and Nakuru Counties. The study was to determine the patient factors which contribute to non-adherence to TB treatment. A purposive sampling method was used to carry out a cross sectional descriptive survey with retrospective cohort of nonadherent TB patients. Target population was smear positive TB patients registered in the TB registers in the two counties, within the past six months at the commencement date of the study. Data was collected using adopted/ developed observation forms/checklists, interview schedules and questionnaires. Respondents were traced non-adherent smear positive TB patients (defaulters), care supporters and health care workers. Collected data was analyzed using SPSS platform. Age, gender, inadequate knowledge, ignorance on need for treatment adherence, stigma, alcoholism, social and economic factors such as low income, lack of social support, low education, financial problems, drug side effects were analyzed. Feeling well soon after medication initiation, drug side effects, low educational level, poor financial status, unemployment, shortage of Tb drugs including unavailability of pyridoxine which is essential in counteracting drug side effects and were associated with defaulting. Staff should also intensify adherence counselling targeting effect of personal factor to adherence. The County of Nakuru and Kericho's Ministry of Health to increase awareness on Tb and make the public aware of the importance of TB control.
\end{abstract}

Keywords: Non-Adherence, TB Treatment, Defaulter, Patient Factor, Tuberculosis

\section{Introduction}

\subsection{Background}

Tuberculosis (TB) is one of the world's deadliest communicable diseases and remains a global public health problem with significant morbidity and mortality.[1, 2] Globally, the tuberculosis (TB) mortality rate has fallen by $41 \%$ since 1990 , and the world is on track to reach the global target of a $50 \%$ reduction during 2015. [3] However, global TB control has faced many challenges, with an estimated 8.7 million incident cases in 2011 and 1.4 million deaths from TB since 2011.

Non adherence to TB treatment leads to high increase in morbidity and mortality, prolonged TB infectiousness, multidrug resistance, relapse and death and high cost of TB treatment which translates to increased burden not only to the nation but to the community TB control interventions. Noncompliance to prescribed drug regimens is a major challenge to attainment of TB treatment goal which is to cure patients 
once they start treatment. Progress in responding to multidrug-resistant TB (MDR-TB) remains slow, [3] particularly in high-burden countries where the incidence of MDR-TB is unacceptably high [3, 4]. In addition, global economic crises and reduced investments in health services threaten national tuberculosis control programs. [3, 5]

The Kenya National Tuberculosis, Leprosy and Lung Disease Program (NTLD-P) has been implementing initiatives towards achieving internationally agreed TB control targets whose immediate short-term goal was to achieve $70 / 85$ targets - that is, to detect $70 \%$ of infectious TB and cure $85 \%$ of the detected cases and then sustain this effort over a long time. The Kenya TB treatment defaulter rate is $15 \%$ [8] Adherence to TB treatment is one of the factors that lead to increase in cure rate and reduction in morbidity and mortality and also decreased emergence of multi drug resistant tuberculosis (MDR TB). Emergence of MDR TB results in high cost of treatment. Though TB does not discriminate on age, sex or education these factors are thought to influence its spread. Previous research in different contexts [7] has shown that there exist many factors influencing non-compliance. They range from individual patient, health care provider, health care delivery patterns and socio-economic related factors.

\subsection{Study Objective}

The study aimed to determine the patient factors which contribute to non-adherence to TB treatment at Kericho and Nakuru Counties of Nakuru County.

\section{Methods}

\subsection{Research Design}

A mixed method research design was used which combined both quantitative and qualitative methods in this study in which closed-ended (quantitative) and open-ended (qualitative) questions. The study utilized a retrospective cohort ( $\mathrm{Tb}$ defaulters) with a mixed method approach comprising both interviews and focus group discussions. Interviews were done to all traced $\mathrm{Tb}$ defaulters, health workers from health facilities where defaulters were traced and focus group discussions with the County Tuberculosis and Leprosy Coordinators (CTLCs) and sub County Tuberculosis and Leprosy Coordinators (sCTLCs) of the two counties of Kericho and Nakuru.

\subsection{Location of the Study}

The study was conducted in urban and rural areas of Kericho and Nakuru Counties in Rift Valley Region. Kericho County has a population of 752,396 and an area of 2,111 $\mathrm{km}^{2}$. It borders Uasin Gishu to the North, Baringo to North East, Nandi to the North West, Nakuru to the East, and Bomet to the South, Nyamira to the South West, Kisii Counties to the South.

Nakuru County has a population of 1.6 million on some 7,495 square kilometres in the central part of the country. It is in the former Rift Valley Province, bordering seven counties with Baringo to the north, Laikipia to the north east, Nyandarua to the east, Kajiado to the south, Narok to the south west with Bomet and Kericho to the west.

\subsection{Study Population}

Target population was Identified smear positive nonadherent TB patients registered in the TB registers in the two counties. Study period was within the past six months at the commencement date of the study in January 2016.

\subsection{Sample Size and Sampling Frame}

A total of 112 smear positive TB patients non-adherent patients from 34 health facilities (24 in Kericho County and 10 in Nakuru county) were purposively identified (62 Kericho County and 50 Nakuru County).

\subsection{Instrumentation/Tools}

Semi-structured interview schedules were used. That was piloted in Emining location of Baringo County, a neighbouring county for the reliability and validity.

\subsection{Procedures for Data Collection}

Data were collected using interviewer guides. Interviews administered by a trained research assistant, who was wellversed and fluent in the local language.

\subsection{Data Analysis}

Data was analysed using SPSS v20. Results presented in graphical summaries.

\subsection{Inclusion Criteria and Exclusion Criteria}

1. Included were ALL registered smear positive non adherent TB patients within the past six (6) months of the study period were recruited for study.

2. Excluded were Transfer-ins and outs and patients with other disease conditions were not included in the study.

\subsection{Ethical Approval and Ethical Considerations}

IREC, Moi University approved the protocol, consent form and interview schedule. An official permission given by CTLCs and sCTLC of the two counties of Nakuru and Kericho, prior to the interviews.

\section{Results}

\subsection{Demographic Factors of Respondents}

The study analysed 112 respondents (50 Nakuru and 62 Kericho) from the two counties of Nakuru and Kericho.

\subsection{Gender of Respondents}

Nakuru County had 29 (58\%) males and 21 (42\%) females while in Kericho county 33 (53\%) were males and 29 (47\%) were females defaulters. This indicates that slightly more 
than half $(58 \%$ and $53 \%$ in Nakuru and Kericho counties respectively) of the defaulters interviewed were males supporting WHO 2003 that males are more likely to have TB than females. Balasubramanian et al 2000, in a study conducted in India found that being male implied twice the risk of abandoning treatment, mainly because workers have trouble in leaving their duties for a health care center visit. Other studies $[15,16,17]$ have shown that the male sex has been identified as a risk factor for treatment discontinuation compounding another study such as that found in Peru where men are more actively employed, albeit their precarious working conditions which often entail: lack of formalized work, lack of unemployment benefits, contracts without vacation time and lack of subsidies for illness, all of which make adherence to treatment even more difficult. However [7] found that female patients adhered most despite cultural practice of seeking permission for treatment from their spouses.

\subsection{Marital Status of the Respondents}

The defaulters' marital status in Nakuru County was; Single 26 (52\%), Married 24 (48\%) while in Kericho county Singles were 34 (55\%) and Married 28 (45\%). These findings indicate that more than $50 \%$ of the defaulters are single which is supported by a study in Kenya (Muture BN, et al, on "Factors Associated with Default among Tuberculosis Patients in Nairobi Province, Kenya: A Case Control Study. BMC Public Health. 2011; 11,696)" [6]-and China [7] (Chee $\mathrm{CB}$, et al, on "Patient and disease characteristics and outcome of treatment defaulters from the Singapore tuberculosis control unit: a one-year retrospective survey. International Journal of Tuberculosis and Lung Disease.2000; 4:496-503)" where patients who were singles had higher risk of defaulting compared to patients who were married. This is contrary to a study in Bangalore, India [10] and Benin city, Nigeria11] which showed that patients who were married had a higher risk of lost to follow up compared to those who were single. A possible explanation could be family responsibility and associated lack of money and time which may have reduced their attention to health care.

\subsection{Age of the Respondents}

The defaulters' mean age in Nakuru County was 33 years with range 66 years (10 to 76) while in Kericho County the mean age was 29 years with range 46 years (15 to 61). Majority of the patients in the two counties were found in the age group 21-39 years with Kericho County having 67\% while Nakuru had $70 \%$. This age group which has more than $65 \%$ of the respondents is also the most economically active age group generally. Other studies have reported a rapid rise in TB morbidity and mortality among this young adult population mostly between $15-44$ years of age $[12,13,14]$ which is in line with the study findings. Other studies mention that patients in extreme age groups (older than 54 and younger than 15) presented a greater tendency towards non-adherence. [15]

\subsection{Level of Formal Education of the Defaulters}

On level of formal education, $30 \%$ and $3 \%$ had no education in Nakuru and Kericho respectively while $40 \%$ and $52 \%$ had Primary education in the two counties respectively. $24 \%$ had Secondary education in Nakuru while 35\% were found in Kericho. $6 \%$ had Tertiary education in Nakuru while $10 \%$ were found in Kericho County. These findings indicate that in Kericho County, $97 \%$ of the defaulters had at least primary level of education and above while in Nakuru County, $30 \%$ of the defaulters had no formal education at all.

\subsection{Patients (Defaulters) Factors}

The respondents were asked questions were patient related such as their occupation, level of income, knowledge regarding $\mathrm{Tb}$, whether they thought $\mathrm{Tb}$ was curable with the current drugs in use, whether they thought $\mathrm{Tb}$ disease was a curse, whether a $\mathrm{Tb}$ patient could share items with others, and whether they had had any other treatment for which they did not complete taking medication. They were also asked whether their defaulting was associated with the responses they gave on the questions asked and also whether their defaulting was associated with length of the $\mathrm{Tb}$ treatment period.

a): Association of Occupation with Non-adherence

When asked whether their defaulting was associated with their occupation the responses given by the defaulters are shown in table 1.

Table 1. Association of Occupation with Non-adherence.

\begin{tabular}{lll}
\hline $\begin{array}{l}\text { Do you associate your occupation with } \\
\text { non-adherence? }\end{array}$ & Nakuru & Kericho \\
\hline & $\%$ & $\%$ \\
\hline Yes & $35(70)$ & $27(44)$ \\
No & $15(30)$ & $35(57)$ \\
Total & $50(100)$ & $62(100)$ \\
\hline
\end{tabular}

The result in table 6 indicates that $70 \%$ and $44 \%$ of the defaulters in Nakuru and Kericho counties respectively associated their defaulting with their occupation while $30 \%$ and $56 \%$ respectively did not associate their non-adherence with occupation in Nakuru and Kericho counties. The findings indicate that $70 \%$ of the defaulters in Nakuru County associated their non-adherence with their occupation, while $56 \%$ in Kericho County did not.

b): Association of Income of the defaulters with Nonadherence

When asked whether their non-adherence was associated with their level of income and hence their financial challenges, the responses from the defaulters are shown in table 2 .

Table 2. Association of income with non-adherence.

\begin{tabular}{lll}
\hline $\begin{array}{l}\text { Do you associate your financial } \\
\text { challenges with non-adherence? }\end{array}$ & Nakuru & Kericho \\
\hline & \% & \% \\
\hline Yes & $42(84)$ & $53(86)$ \\
No & $8(16)$ & $9(14)$ \\
Total & $50(100)$ & $62(100)$ \\
\hline
\end{tabular}


The responses in table 8 indicate that $84 \%$ and $86 \%$ of the respondents agreed that their non-adherence was due to financial challenges in Nakuru and Kericho counties respectively while $16 \%$ and $14 \%$ did not associate their nonadherence with their financial challenges. These findings indicate that more than $80 \%$ of the defaulters in the two counties defaulted because of their financial challenges.

c): Understanding TB Disease

Study results indicate that $94 \%$ and $95 \%$ of the patients knew the disease they were suffering from while $6 \%$ and $5 \%$ did not understand the disease in Nakuru and Kericho counties respectively. These findings indicate that more than $90 \%$ of the defaulters knew the disease they were suffering from.

d): Non-adherence Association with Discomfort or Drug side effects during Treatment

The defaulters were asked if they associated their nonadherence with discomfort or drug side effects they felt during treatment. The result indicates that $76 \%$ and $26 \%$ of the respondents in Nakuru and Kericho counties respectively associated their non-adherence to discomfort or drug side effects they felt during treatment, while $24 \%$ and $74 \%$ respectively did not. The responses indicate that in Nakuru County, $76 \%$ of the defaulters associated their non-adherence with discomfort or side effects while $74 \%$ of Kericho County defaulters did not.

In Nakuru County, one defaulter, a 54 year-old male who discontinued both his anti-TB and ART treatment after experiencing severe side effects explained:

......"I continued the drugs but the nightmares and the hunger became too much. And then, I don't really even know how, my mind was also disturbed, so I took the drugs for some time, and stopped all drugs. You know the nightmare! And since I had no one beside me, and since the medications were disturbing me at night, and since it was pushing me to run away, I got scared and stopped the drugs."...... (54 yearold male Tb defaulter).

Another defaulter, a 36 year old female in Kericho County said she had to default when she noticed change in colour of her urine and had this to say "......My urine turned red; I thought it was blood caused by the medication. I thought it was safer to stop the medication......"

e): Length of Treatment Period and Non-adherence

When asked whether their non-adherence was associated with the length of treatment period.

The result indicates that $90 \%$ and $34 \%$ of the respondents attributed their non-adherence with the length of treatment period in Nakuru and Kericho counties respectively, while $10 \%$ and $66 \%$ did not, respectively. This indicates that $90 \%$ of the defaulters in Nakuru County attributed their nonadherence with length of treatment period while $66 \%$ did not in Kericho County.

f): Tb Patients sharing their items with others

When the defaulters were asked whether they can share their items with others.

The result indicates that $82 \%$ and $55 \%$ of the defaulters in Nakuru and Kericho counties respectively stated that they can share their items with others, while $18 \%$ and $45 \%$ in the two counties respectively did not agree. The finding in this table indicates that more than $80 \%$ of the defaulters in Nakuru County were willing to share their items with others, while $45 \%$ in Kericho County were not willing.

g): Other unfinished Treatment

The defaulters were also asked whether they had had any other treatment which they never finished.

The result indicates that $60 \%$ and $66 \%$ of the respondents in Nakuru and Kericho counties respectively admitted that they never finished other treatment they had had before, while $40 \%$ and $34 \%$ declared they finished the treatment started earlier. From this response it indicates that more than $60 \%$ of the defaulters never finished treatments started earlier before the current $\mathrm{Tb}$ treatment.

\subsection{Health Workers' Views on Patients' Defaulting}

Some of their responses when asked about their views on possible reasons for default from $\mathrm{Tb}$ Treatment by patients are as follows:

On how alcoholism contributes to non-adherence to $\mathrm{Tb}$ medication, 24 out of 35 healthcare workers in Kericho County had this to say from their experience ".......majority of those who are alcoholic forget to take their medication when under the influence of alcohol, and fear to come to health facility since instructions given when starting treatment is that they should not take alcohol while under medication, and since they have breached this instructions they fear to face the daktari ( doctor - referring to health worker)....."

Soon after taking medication many patients begin to feel well and thus do not feel any obligation to continue taking medication and hence default from medication. On this, 21 out of 35 and 8 out of 14 healthcare workers interviewed in Kericho and Nakuru counties respectively said that ".....once patients feel better after a few days of taking medication, they imagine that they are now cured and see no reason to take medication anymore thus defaulting from medication..."

Regarding stigma and its relationship to non-adherence to treatment, $51 \%$ (18 out of 35 ) of the healthcare workers interviewed in Kericho county had this to say on how stigma contributes to medication non-adherence ".....most of the patients go into denial due to possible association of their disease with HIV as they feel that they are culturally or socially unacceptable or inferior so they become withdrawn, fearful, silent, and secretive and this prevents them from talking about their condition even to those who are close to them and love them....."

On drug fatigue - i.e. too many drugs and prolonged period of intake -pill burden, $43 \%$ (6 out of 14) and 29\% (10 out of $35)$ of the healthcare workers interviewed in Nakuru and Kericho counties respectively stated that from the perspective of some patients, a high number of pills was associated with potential damage to the body and a higher risk of not tolerating the drugs thus, summing up what one patient stated: Swallowing so many drugs, was very difficult. I was scared that it would harm my body. Drugs can harm you if they are 
too many."(36-year-old male defaulter in Kericho County). This belief was reinforced by some $43 \%$ of healthcare workers in Nakuru County who also narrated: ...."When they think about pill burden, they say, can I tolerate this, won't this kill me? Taking many pills is perceived as lethal by some. Patients worry a lot about whether their body will be able to handle so many pills every day."

Regarding drug side effects, according to $36 \%$ (5 out of 14) of healthcare workers interviewed in Nakuru County, some defaulters abandon taking medication citing side effects as reason for non-adherence stating that patients tend to experience side effects mainly at the beginning of anti-TB treatment or upon initiation of concomitant treatment, with some side effects mentioned being: generalized body weakness, burning of the stomach, "turning of the head", headache, bad dreams, rash and vomiting.

\section{Summary}

The study found the following to be patient factors associated with defaulting

a) Patient factors

1. Feeling well soon after consistently/uninterrupted medication intake

2. Alcoholism - patients tend to forget to take medication when drunk

3. Denial due to possible association with HIV

4. Drug side effects and associated feeling unwell following drug intake.

5. Drug fatigue - too many drugs and prolonged period of intake - pill burden

6. No food, cannot take drugs on an empty stomach

7. Not appreciating seriousness of Disease - because of low educational level

\section{Conclusion}

The study concludes that Patient factors leading to nonadherence range from Feeling well soon after medication, Alcoholism, self-denial, Drug side effects, pill burden, lack of food and low educational level. These are factors that are patient centred. Solution lies in patient Health Education that will lead to behaviour change that directly affects the patient's adherence to Tuberculosis treatment. The Health care provider should be aware of these factors as he/she delivers the service for successive disease cure rate.

\section{Recommendations}

The study recommends the following:

Staff to intensify adherence counselling to $\mathrm{Tb}$ patients on identified patient and socio cultural factors.

Conduct regular update workshops to healthcare workers and volunteers on $\mathrm{Tb}$ disease and its management and medical counselling skills. Also develop and avail Education materials such as informational pamphlets, instructions for therapy, behaviours to prevent $\mathrm{Tb}$ transmission, medical alerts, and descriptions of TB and widely distribute to general public in order to increase awareness on $\mathrm{Tb}$ and make the public aware of the importance of TB control.

To conduct further research to identify behavioural and social factors that can improve patient adherence and treatment completion.

\section{References}

[1] World Health Organization (WHO) (2012) Global Tuberculosis Report 2012. Geneva: WHO,.http://www.who.int/iris/bitstream/10665/75938/1/9789 241564502_eng.pdf. Accessed April 15, 2013).

[2] Raviglione, M., Marais, B., Floyd, K., Lönnroth, K., Getahun, H., Migliori, G. B. \& Chakaya, J. (2012). Scaling up interventions to achieve global tuberculosis control: progress and new developments. The Lancet, 379 (9829), 1902-1913.

[3] Jensen, P. A., Lambert, L. A., Iademarco, M. F., Ridzon, R., \& Centers for Disease Control and Prevention. (2005). Guidelines for preventing the transmission of Mycobacterium tuberculosis in health-care settings, 2005. Atlanta, GA: US Department of Health and Human Services, Public Health Service, Centers for Disease Control and Prevention.

[4] Centers for Disease Control and Prevention. (2005). Guidelines for preventing the transmission of Mycobacterium tuberculosis in health-care settings, 2005. $M M W r, 54$ (RR-17), 2-107.

[5] Mohamed I. M. I, Abdul W, Al S, Adel (2013) Factors affecting patients' compliance to anti-tuberculosis treatment in Yemen, Journal of Pharmaceutical Health Services Research 4 (2), 115-122.

[6] Bagoes W, Michelle G, Maartje D. (2009) Factors that influence treatment adherence of tuberculosis patients living in Java, Indonesia Dovepress Journal 3, 231- 238.

[7] Salla A. M, Simon A. L, Helen J. S, Mark E. E, Atle F, Jimmy V (2007) Patient Adherence to Tuberculosis Treatment: A Systematic Review of Qualitative Research DOI: 10.1371/journal.pmed.0040238.

[8] World Health Organization. (2013) Global tuberculosis report 2013.

http://apps.who.int/iris/bitstream/10665/91355/1/9789241564 656_eng.pdf?ua=1. Access 2014 June 2.

[9] Zhao Y, Xu S, Wang L, Chin DP, Wang S, Jiang G, (2012) National survey of drug-resistant tuberculosis in China. New England Journal Medicine. 366:2161-2170. doi: 10.1056/NEJMoa1108789.

[10] Vijay S, Balasangameswara VH, Jagannatha PS, Saroja VN and Kumar P (2003) Defaults among Tuberculosis Patients Treated under DOTS in Bangalore City: A Search for Solution. Indian Journal of Tuberculosis.; 50, 185-196.

[11] Xu W, Lu W, Zhou Y, Zhu L, Shen H and Wang J (2009). Adherence to Anti-Tuberculosis Treatment among Pulmonary Tuberculosis Patients: A. Qualitative Study. BMC Health Service Research; 9, 169.

[12] World Health Organization Global Tuberculosis Report 2013.www.who.int(Accessed on 5th May 2014). 
[13] Warker R. and Edward C (2004) The Chemotherapy of Tuberculosis. Clinical Pharmacy and Therapeutic. 3rd Edition. Churchill Livingstone., pp 583-93.

[14] Ministry of Health: National Leprosy and Tuberculosis Guideline (MOH/NLTP),

2005.http://www.nltp.co.ke/docs/National_NLTP_Guideline.p df(Accessed on March 19th, 2014).

[15] Burman, W. J., Cohn, D. L., Rietmeijer, C. A., Judson, F. N., Sbarbaro, J. A., \& Reves, R. R. (1997). Short-term incarceration for the management of noncompliance with tuberculosis treatment. Chest, 112(1), 57-62.
[16] Jha, U. M., Satyanarayana, S., Dewan, P. K., Chadha, S., Wares, F., Sahu, S.,... \& Chauhan, L. S. (2010). Risk factors for treatment default among re-treatment tuberculosis patients in India, 2006. PLoS One, 5(1), e8873.

[17] Horna-Campos, O. J., Consiglio, E., Sánchez-Pérez, H. J., Navarro, A., Caylà, J. A., \& Martín-Mateo, M. (2010). Pulmonary tuberculosis infection among workers in the informal public transport sector in Lima, Peru. Occupational and environmental medicine, oem-2009. 